\title{
Desenvolvimento de Protótipo de Game para Inserção no Ensino de Ciências
}

\author{
Cleon X. Pereira Júnior ${ }^{1}$, Zara Hoffmann ${ }^{1}$, \\ Caroline P. Castro ${ }^{1}$, Geovanna S. Santos ${ }^{1}$, Thaís A. Aires ${ }^{1}$ \\ ${ }^{1}$ Instituto Federal Goiano (IF Goiano) \\ Rua Rui Barbosa Qd 13 Lt. 1-A Setor Aeroporto - Campos Belos - GO - Brazil
}

Este trabalho teve apoio financeiro do PIPECTI / IF Goiano para apresentação.

\{cleon.junior, zara.hoffmann\}@ifgoiano.edu.br

\begin{abstract}
The use of Information and Communication Technologies in the educational environment indicates a possibility of educators and students exercise their own citizens through the use of technology. In this context, the development of diversified didactics actions which combine scientific knowledge to decisions taken on a day-to-day that stimulate significant approaches of understanding scientific knowledge, it becomes a possible alternative, both for the development of software systems and for the Science teaching. Within a development proposal of creativity and initiative, this work aims beyond the interdisciplinary interaction between software development areas with common base classes, it is also going to develop a technological prototype in a game format to be applied in Education Science. We intend apply to freshman students, who had presented a large gap of scientific content, after diagnosis survey.
\end{abstract}

Resumo. O uso das Tecnologias da Informação e Comunicação no meio educacional aponta para uma possibilidade de professores e alunos exercerem sua própria cidadania por meio do uso das tecnologias. Neste contexto, o desenvolvimento de ações didáticas diversificadas que aliem saberes científicos às decisões tomadas no dia-a-dia que estimulem abordagens significativas para compreensão dos conhecimentos científicos, torna-se uma alternativa possivel, tanto para o desenvolvimento de sistemas de softwares quanto para o Ensino de Ciências. Dentro de uma proposta de desenvolvimento da criatividade e iniciativa este trabalho tem como objetivo além da interação interdisciplinar entre áreas de desenvolvimento de softwares com disciplinas da base comum, desenvolver um protótipo tecnológico em formato de jogo para ser aplicado no Ensino de Ciências. Pretende-se aplicar o protótipo entre os alunos ingressantes, os quais apresentaram grande defasagem de conteúdos científicos, após levantamento diagnóstico.

\section{Introdução}

O termo Tecnologia da Informação e Comunicação (TIC) é usado no contexto educacional para relacionar tanto a educação conectada à internet e seu aspecto social, quanto o uso educacional das tecnologias da informação e comunicação tais como a televisão, o computador e outras mídias digitais. Numa visão determinista, conforme 
[Hato Sánchez and Vargas Lema 2013], tais tecnologias apontam para um conjunto de inovações tecnológicas e, seu conjunto de ferramentas, proporcionam uma redefinição radical do comportamento e funcionamento da sociedade contemporânea. Já na visão instrumentalista de [Castels and em Rede 1999], "a tecnologia não determina a sociedade; incorpora-a" visto que há um conjunto de fatores que intervêm nos processos societários, interativos e complexos, como a criatividade e a própria tecnologia. Esta forma de perceber a tecnologia considera-a um instrumento "neutro" utilizada com a finalidade de ter acesso ao conhecimento, também visto como neutro. A essa dualidade de pensamento [Peixoto and dos Santos Araújo 2012] descrevem como racionalidade instrumental: "um movimento que oscila entre a visão da tecnologia como ferramenta [..] e a atribuição à tecnologia o poder de configurar a cultura e a sociedade", e é esta racionalidade que permeia os projetos pedagógicos de inserção das TICs nos meios educacionais.

Nas relações entre escola e TIC, ao pensar de forma acrítica sobre as visões, tanto a determinista quanto a instrumentalista, corre-se o risco de acreditar que: 1 - prover a escola de aparatos tecnológicos, como computadores, tablets, lousa digital, entre outros, propiciará a inclusão digital dos alunos; 2 - ficar contra a inserção das TIC nas escolas, numa posição defensiva, protegerá os alunos e professores da desigualdade facilitada pelas TIC, e 3 - focar na capacitação a priori para uso das TIC, de fora para dentro da escola, pode excluir as possibilidades de apropriação dessas TIC de forma a impedir as mudanças escolares nas suas inadequações. Como deixa transparecer [BUZATO 2006] ao "conceber a tecnologia como ação social coletiva" é possível identificar além das necessidades de infraestrutura e formação, as possibilidades de professores e alunos exercerem sua própria cidadania através do uso das tecnologias.

Para uma prática educativa que atenda tanto os requisitos da Inclusão Digital quanto os Parâmetros Curriculares Nacionais para o Ensino Médio (PCNEM), pautada na interdisciplinaridade, contextualização e desenvolvimento de competências e habilidades, não é possível que o professor se atenha ao livro didático apenas, o qual proporciona um entendimento periférico e fragmentado dos conhecimentos [SEMTEC 1999]. Neste contexto, o Ensino Tecnológico pode contribuir na construção da cidadania, isto é, formar cidadãos capazes de participar criticamente na sociedade, através de uma proposta de ações didáticas inovadoras, com a incorporação das Tecnologias de Informação e Comunicação. Igualmente, entende-se que o Ensino de Ciências ainda é pautado por uma grande quantidade de conceitos teóricos e que a falta de metodologias alternativas voltadas para um aprendizado lúdico e motivador, dificulta o processo de aprendizagem, levando os alunos à memorização em nível superficial. Numa proposta de estratégias motivacionais, dinâmicas e inovadoras, o uso de jogos educativos pode suprir a dificuldade de se ministrar aulas experimentais devido à falta de laboratórios. Porém, mais que o domínio das tecnologias, desenvolver nos alunos habilidades mentais e pessoais, tais como criatividade, iniciativa, espírito crítico e colaborativo, sociabilidade e capacidade de transformar informações que recebe em conhecimento útil [TIBÚRCIO 1997]. E é nesse sentido que este trabalho propõe o desenvolvimento de uma aplicação no formato de jogo para aprendizagem de conceitos de ciências naturais.

\section{Jogos no ensino de ciências}

Os jogos, ou elementos de jogos, estão inseridos cada vez mais no meio educacional, e é possível encontrá-los para o ensino das mais diversas disciplinas. Para o ensino de 
ciências, [Li and Tsai 2013] apresentam uma revisão dos trabalhos mais relevantes que utilizam jogos ou estratégias de jogos. Na pesquisa é apontada que a partir de 2006 houve um crescimento no uso de jogos para a aprendizagem. Os trabalhos levantados na pesquisa apontam os jogos para trabalhar conceitos, processos científicos, resolução de problemas, afetividade, engajamento ou aprendizagem contexto-social.

Mais específico para o ensino de química, existe uma gama de trabalhos que demonstram o uso de jogos para maior efetividade do ensino. [Boletsis and McCallum 2013] apresentam, através da realidade aumentada, um jogo colaborativo para o ensino da tabela periódica. Já [Capps 2008] apresenta o uso de um jogo de tabuleiro para o reforço dos conceitos básicos de química. Desta forma, é possível ver que, de diferentes formas, os jogos vem crescendo para engajar mais o estudante na aprendizagem, tornando estratégias pedagógicas durante o ensino.

\section{O jogo - Os elementos químicos no meio ambiente}

O jogo, proposto aqui, tem como enredo a história de um garoto chamado Caio que está a caminho de casa, sendo que o mesmo deve chegar antes do sol se pôr. Durante o caminho, o jogador terá que resolver alguns problemas para permitir que o garoto prossiga. Por exemplo, para atravessar o primeiro obstáculo, o usuário terá que selecionar, dentre os compostos, qual deles representa a água. Respondendo corretamente, o lugar que era um vão, aparecerá um rio e permitirá que o mesmo atravesse, conforme apresentado na figura 1. Outros desafios como o plantio de árvore para a sobrevivência (Relação do oxigênio com o gás carbônico), combustão do fogo para o aquecimento, etc, são apresentados permitindo que o jogador enxergue os elementos químicos presentes na natureza.
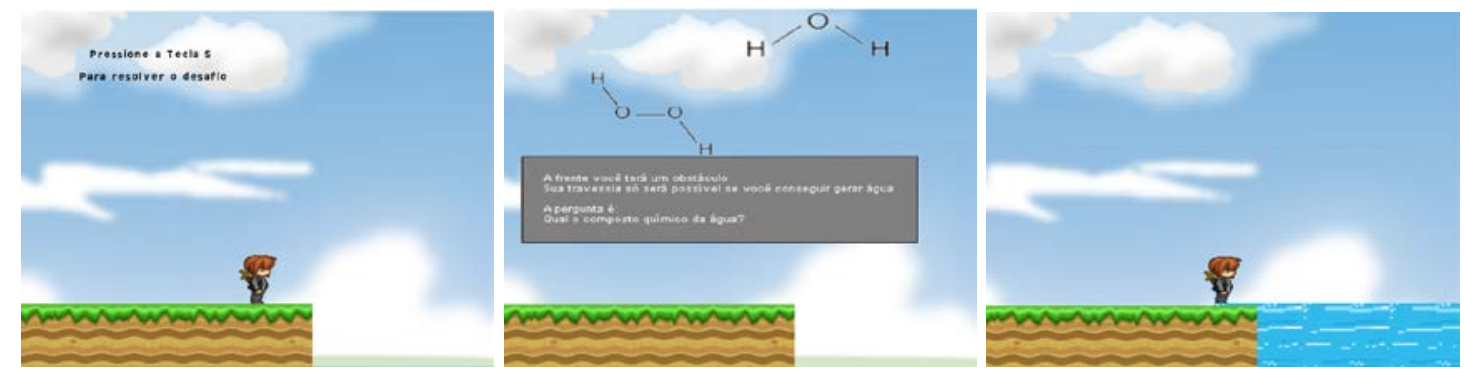

Figura 1. Personagem em frente ao obstáculo; o desafio para atravessá-lo; Desafio cumprido

Caracterizado como uma pesquisa qualitativa, este trabalho vem sendo desenvolvido com a utilização de diversas estratégias de investigação. A princípio foram utilizados dados da avaliação diagnóstica efetuada pelos professores com alunos ingressantes, com a finalidade de detectar suas dificuldades específicas. Esta investigação permitiu determinar o nível de conteúdo científico a ser trabalhado no jogo, sendo a química e a educação ambiental escolhido como foco principal.

O jogo é dividido em fases, onde os acertos permitem que o estudante prossiga e os erros fazem com que o mesmo sofra uma penalidade, perdendo uma porcentagem da vida. Desta forma, acredita-se que o estudante terá uma oportunidade a mais de revisar os conceitos básicos de química e associá-los no meio ambiente entendendo a necessidade dos elementos. 
Para o desenvolvimento do jogo foi utilizado o Game Maker Studio ${ }^{1}$ pela facilidade na criação de cenários e possibilidades geradas pelo mesmo. A documentação foi baseada no padrão de jogos, o Game Design. Durante o desenvolvimento foram utilizadas estratégias de engenharia de software, como testes de caixa preta na verificação de erros ou inconsistências.

\section{Considerações Finais}

Este trabalho apresentou uma estratégia, utilizando um protótipo de game, para o ensino de química e educação ambiental. Espera-se que, desta forma, os estudantes tenham a possibilidade de aprender ou revisar os conteúdos básicos de química de uma forma divertida, contextualizando e entendendo a necessidade dos compostos no meio ambiente.

Como próxima etapa, haverá uma aplicação do protótipo em turmas iniciantes do ensino médio no Instituto federal, procurando assim, enriquecer mais os conhecimentos científicos, onde os mesmos apresentam uma grande defasagem. Espera-se, ainda como continuação deste trabalho, uma melhoria na interface do jogo, enriquecendo com elementos e animações que levem a concentração do jogador. Também espera-se criar novos enredos com objetivos distintos para aprimorar ainda mais o conhecimento dos usuários.

\section{Referências}

Boletsis, C. and McCallum, S. (2013). The table mystery: An augmented reality collaborative game for chemistry education. In Serious Games Development and Applications, pages $86-95$. Springer.

BUZATO, M. E. K. (2006). Letramentos digitais e formação de professores. In III Congresso Ibero-Americano EducaRede, volume 29.

Capps, K. (2008). Chemistry taboo: An active learning game for the general chemistry classroom. Journal of chemical education, 85(4):518.

Castels, M. and em Rede, A. S. (1999). A era da informação: economia, sociedade e cultura. São Paulo: Paz e Terra, 3.

Hato Sánchez, M. A. and Vargas Lema, S. T. (2013). El uso de las tics como instrumento pedagógico en el proceso educativo de los estudiantes de bachillerato en químico biólogo del i.t.s. república del ecuador durante el año lectivo 2011-2012.

Li, M.-C. and Tsai, C.-C. (2013). Game-based learning in science education: a review of relevant research. Journal of Science Education and Technology, 22(6):877-898.

Peixoto, J. and dos Santos Araújo, C. H. (2012). Tecnologia e educação: algumas considerações sobre o discurso pedagógico contemporâneo. Educação \& Sociedade, 33(118):253-268.

SEMTEC, M. (1999). Parâmetros curriculares nacionais para o ensino médio. Brasília: Secretaria de Educação Média e Tecnologia.

TIBÚRCIO, C. (1997). Guia de informática e internet para a educação brasileira. São Paulo.

\footnotetext{
${ }^{1}$ Game Maker Studio: Motor de jogo com suporte à linguagem GML, disponível em http://yoyogames.com/
} 